\title{
SUBVENÇÕES GOVERNAMENTAIS: UMA ANÁLISE DA RELAÇÃO ENTRE O NÍVEL DE EVIDENCIAÇÃO E AS CARACTERÍSTICAS DAS COMPANHIAS DE CAPITAL ABERTO BRASILEIRAS
}

\author{
Monique Marcelino ${ }^{1}$, Maíra Melo de Souza ${ }^{2}$ \\ 1'monique.marcelino@hotmail.com \\ 2mairameloufsc@gmail.com
}

\section{Resumo}

O objetivo deste trabalho foi verificar a relação entre o nível de evidenciação das subvenções governamentais e as características das companhias de capital aberto brasileiras. Para tanto, foi elaborada uma lista de verificação, com base no pronunciamento técnico CPC 07 (R1), abordando os requisitos estabelecidos pelo referido pronunciamento, quanto à correta evidenciação das subvenções governamentais nos demonstrativos contábeis e notas explicativas. Por meio da lista de verificação foi possível medir o nível de evidenciação das companhias analisadas e, relacionar com as principais características das companhias, como: i) empresa de auditoria, ii) resultado do exercício social e iii) classificação de subsetor. Além disso, elaborou-se um ranking com os maiores e menores níveis de evidenciação apurados na amostra. Os documentos analisados foram: Demonstração do Resultado do Exercício (DRE), Balanço Patrimonial (BP) e as notas explicativas referentes ao ano de 2016 de 260 companhias que apresentaram algum tipo de subvenção governamental em seus demonstrativos contábeis. Os resultados da pesquisa demonstraram que as companhias brasileiras analisadas, em sua maioria, possuem um baixo nível de evidenciação das subvenções governamentais, em que apenas 26 companhias da amostra obtiveram um nível de evidenciação igual ou superior a 50\%. Concluiu-se, também, que os resultados da pesquisa não sugerem tendência de relação entre as características analisadas (empresa de auditoria, resultado do exercício e subsetor) com o baixo nível de evidenciação das companhias.

Palavras-Chave: Subvenção governamental. Subvenções governamentais. CPC 07 (R1). Evidenciação contábil.

\section{GOVERNMENT GRANTS: AN ANALYSIS OF THE RELATIONSHIP BETWEEN THE LEVEL OF DISCLOSURE AND THE CHARACTERISTICS OF PUBLICLY TRADED BRAZILIAN COMPANIES}

\section{Abstract}

The objective of this study was to verify the relationship between the level of disclosure of government grants and the characteristics of Publicly Traded Brazilian Companies. For this purpose, a checklist was prepared, based on technical pronouncement CPC 07 (R1), addressing the requirements established by said pronouncement, regarding the correct disclosure of government grants in the financial statements and explanatory notes. Through the checklist it was possible to measure the level of disclosure of the companies analyzed and to relate to the main characteristics of the companies, such as: i) auditing company, ii) results of the fiscal year, and iii) subsector classification. In addition, a ranking was made with the highest and lowest levels of disclosure found in the sample. The documents analyzed were: The Statement of Income (DRE), Balance Sheet (BP) and the explanatory notes for the year 2016 of 260 companies that presented some type of government grant in their financial statements. The results of the research showed that the majority of Brazilian companies have a low level of

R. Eletr. do Alto Vale do Itajaí - REAVI, v. 7, n. 11, p. 01-09, dez., 2018 ISSN: 2316-4190, DOI: $10.5965 / 2316419007112018131$ 


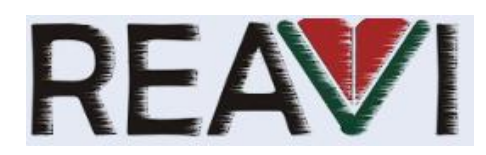

\section{Universidade do Estado de Santa Catarina \\ Centro de Educação Superior do Alto Vale do Itajaí}

disclosure of government grants, in which only 26 sample companies obtained a disclosure level equal to or greater than 50\%. It was also concluded that the results of the research do not suggest a tendency of relation between the characteristics analyzed (audit firm, result of the exercise and subsector) with the low level of disclosure of the companies.

Keywords: Government grant. Government grants. CPC 07 (R1). Disclosure.

\section{Introdução}

Considera-se como subvenções governamentais o auxílio governamental concedido pelo Governo às entidades, seja por contribuição de natureza pecuniária ou outras, desde que possam ser quantificadas em dinheiro e distinguidas das demais operações comerciais da entidade. Em troca deste auxílio, é cobrado das entidades o cumprimento passado ou futuro das condições impostas, condições estas ligadas as atividades operacionais da empresa em questão (CPC 07 R1, 2010).

As empresas beneficiadas pelo recebimento de subvenções governamentais no Brasil possuem como normatização, para a oportuna evidenciação, o Pronunciamento Técnico CPC 07 (R1), que aborda as Subvenções e Assistências Governamentais, correlato à Norma Internacional de Contabilidade International Accounting Standards (IAS) 20, emitida pelo International Accounting Standards Board (IASB).

Diante da complexa realidade do mundo corporativo brasileiro o Governo possui um importante papel em ofertar auxílio às empresas para subsidiar e incentivar o ofício das mesmas por meio de subvenções governamentais, bem como estimular o desenvolvimento de determinadas regiões ou setores da economia. Corroborando com esta assertiva, o estudo de Souza (2009) explica que o Governo pode reduzir as desigualdades regionais por meio do aumento dos efeitos propulsores do polo urbano-industrial, isto é, regionalizando os gastos públicos, alocando-os em áreas atrasadas, sobre tudo em infraestrutura para o alcance de uma maior igualdade entre as regiões.

No que se refere à evidenciação contábil, com a modernização dos processos e gestão de trabalho, derivado da globalização e o leque de acesso às informações que normatizam procedimentos, como o Comitê dos Pronunciamentos Contábeis (CPC) no Brasil, tornam-se imprescindíveis o fácil acesso e compreensão dos fatos ocorridos nas entidades por meio das informações geradas pelo profissional contábil. É por meio desta demanda que o IASB tem o papel de emitir pronunciamentos que divulguem os parâmetros para a elaboração das demonstrações financeiras das companhias a nível global e de alta qualidade (FERNANDES; SANTOS; SCHMIDT, 2006).

Visto isso, a partir do momento em que a entidade é contemplada com algum tipo de subvenção governamental, esta, por sua vez, tem como contrapartida, além das obrigações impostas para o recebimento da assistência, também, a evidenciação das informações necessárias e suficientes da operação, previstas pelo CPC 07 (R1, 2010), que trata justamente desta adequada evidenciação.

O CPC 07 (R1, 2010) também enuncia que o reconhecimento do recebimento da subvenção governamental não deve ser registrado em contrapartida do resultado do exercício até que se tenha a plausível segurança de que a entidade cumprirá todas as condições que foram estabelecidas para o recebimento da mesma. Desta forma, enquanto não cumpridas tais condições do contrato, as subvenções devem ser apresentadas no passivo.

Considerando o exposto, é de suma importância que as entidades beneficiadas divulguem adequadamente as informações sobre a subvenção recebida, visto que utilizaram de recursos públicos para fins particulares da entidade, com o intuito de retornarem, beneficiando a população, uma região e/ou um setor da economia.

R. Eletr. do Alto Vale do Itajaí - REAVI, v. 7, n. 11, p. 01-09, dez., 2018 ISSN: 2316-4190, DOI: $10.5965 / 2316419007112018131$ 
de evidenciação das subvenções governamentais e as características das companhias de capital aberto brasileiras? O objetivo desta pesquisa é verificar a relação entre o nível de evidenciação das subvenções governamentais e as características das companhias de capital aberto brasileiras.

Esta pesquisa é relevante, visto que coloca em evidência um tema relativamente novo no Brasil, no que diz respeito ao tratamento contábil e evidenciação das subvenções governamentais, que teve a influência da adoção das Normas Internacionais de Contabilidade (IFRS) por meio das alterações na Lei n. ${ }^{\circ}$ 6.404/1976 promovida pelas Leis n. ${ }^{\circ}$ 11.638/2007 e n. ${ }^{\circ} 11.941 / 2009$ e pela emissão dos pronunciamentos contábeis do CPC. Outro tópico relevante apontado nesta pesquisa é de guiar, de maneira geral, maior conhecimento sobre o tema abordado, visto que se trata de subsídios concedidos pelo Governo para beneficiar, de maneira indireta, a população como um todo.

Esta pesquisa delimita-se a analisar o Balaço Patrimonial, Demonstração do Resultado do exercício e as Notas Explicativas, do exercício social de 2016, das companhias de capital aberto listadas na Bolsa de Mercadorias \& Futuros e Bolsa de Valores do Estado de São Paulo (BM\&FBOVESPA), atualmente Brasil, Bolsa, Balcão (B3), que receberam algum tipo de subvenção governamental. Por meio da análise documental o exposto trabalho explana o estudo sobre os tratamentos adequados as subvenções governamentais por parte das entidades beneficiadas, de acordo com a normatização do pronunciamento do CPC 07 (R1, 2010) que, também, norteou a elaboração da lista de verificação, com as principais questões a serem averiguadas das entidades, configurando o instrumento principal da pesquisa para a análise da evidenciação.

\section{Fundamentação teórica}

\subsection{Subvenções Governamentais}

As subvenções governamentais são ações efetuadas pelo do Governo por meio de repasses de contribuições pecuniárias, incentivos fiscais, doações, prêmios e outros meios de subsídios às entidades, em troca do cumprimento de exigências estabelecidas que sejam relacionadas às atividades operacionais das entidades pelo Governo (RIOS; MARION, 2017).

Seguindo o mesmo entendimento, os autores Muller e Scherer (2011) definem como subvenções governamentais as ajudas do setor público em forma de transferências de recursos a uma empresa em compensação ao cumprimento de certas condições relativas às suas atividades de operação.

O CPC 07 (R1, 2010) exprime que não são consideradas como subvenções governamentais as assistências do Governo que não podem ser razoavelmente quantificadas em dinheiro e as transações com o Governo que não podem ser distinguidas das operações comerciais normais da empresa. Além disso, o referido pronunciamento do CPC (2010) demonstra alguns exemplos de subsídios do Governo que possam ser considerados como subvenções governamentais, tais como: recebimento de ativos, como máquinas para auxiliar na produção da empresa ou terreno para a construção de novas estruturas, a dispensa legal do pagamento de tributo, seja através de isenção, imunidade ou redução de tributos e o empréstimo subsidiado, que se caracteriza pela renúncia por parte do credor em receber parte ou o total do empréstimo e/ou juros recorrente dele.

No Brasil até o ano 2017, o tratamento disposto às subvenções governamentais para investimento era de realizar a evidenciação das mesmas como reservas de capital no patrimônio líquido. Com a publicação da Lei n. ${ }^{0} 11.638 / 2007$, a partir de $01 / 01 / 2008$, ficou vedado às contabilizações como reservas de capital e passou a vigorar o tratamento contábil que reconhece as subvenções governamentais de imediato ou à medida de sua realização, no resultado do

R. Eletr. do Alto Vale do Itajaí - REAVI, v. 7, n. 11, p. 01-09, dez., 2018 ISSN: 2316-4190, DOI: $10.5965 / 2316419007112018131$ 
exercício, desde que comprovado a garantia de cumprimento das obrigações impostas à empresa, (RIOS; MARION, 2017).

A forma como a subvenção governamental é recebida pela entidade não interfere no método de evidenciação que deve ser adotado, isto é, a entidade beneficiada deve realizar a evidenciação conforme estabelece o CPC 07 (R1, 2010) para o tipo de subvenção recebida, independente do embolso ser em dinheiro ou redução de passivo.

Outro preceito abordado pelo CPC $07(\mathrm{R} 1,2010)$ adverte que, enquanto não houver a certeza dos cumprimentos estabelecidos à entidade para o recebimento da subvenção governamental, a contrapartida do registro no ativo do balanço patrimonial da entidade deve ser registrada no passivo, em conta específica e, só após a consumação dos cumprimentos estabelecidos é que a empresa deverá reconhecer o benefício como receita na demonstração do resultado.

É possível perceber que as subvenções governamentais desempenham um importante papel em subsidiar as atividades das entidades por ela beneficiadas e que, por meio de ações como essas, o Governo consegue, de alguma forma, investir para fomentar a economia de regiões específicas, bem como, de setores da economia desprovidos de capital para a continuidade de seus negócios e desenvolver a região como um todo, beneficiando a população local com mais empregos, oportunidades e infraestrutura.

\subsection{Evidenciação Contábil (Disclosure)}

A evidenciação contábil tem como principal papel nortear a elaboração das demonstrações contábeis, de modo a atender as finalidades e necessidades específicas dos diversos usuários das informações contábeis, (ESTRUTURA CONCEITUAL PARA ELABORAÇÃO E DIVULGAÇÃO DE RELATÓRIO CONTÁBIL-FINANCEIRO, 2011).

Nesta concepção, Iudícibus (2015) explica que a evidenciação é um compromisso inalienável da contabilidade para com seus usuários, com os próprios objetivos e, que mesmo com a possibilidade de variação das formas de evidenciação de entidade para entidade, a essência deverá ser sempre a mesma: apresentar informações quantitativas e qualitativas de maneira ordenada, a fim de deixar uma base adequada de informação para o usuário.

Consoante com Niyama e Silva (2013), um dos principais benefícios pretendidos pela divulgação dos pronunciamentos contábeis é que seja possível comparar as informações contábeis produzidas pelas companhias em diferentes países, permitindo assim, a compreensão e a interpretação dos dados gerados por entidades de economias e tradições diferentes.

Para os autores Santos, Schimidt e Machado (2005), as informações contábeis não possuem mais fronteiras espaciais e temporais, sendo possível o acesso à informação contábil a qualquer hora e lugar pelos mais diversos tipos de usuários. Visto isso, é de suma importância que os demonstrativos contábeis estejam alinhados com as normas reguladoras, para que as informações possam ser compreendidas de maneira clara e objetiva.

Weffort (2005) afirma que na contabilidade o profissional contábil é o responsável por produzir informações e transmiti-las aos destinatários, que são todos os usuários, sejam eles pertencentes à organização (internos), como também, os investidores, governo, credores e outros (externos).

No que se refere à evidenciação contábil das subvenções governamentais o CPC 07 (R1, 2010), explica que é necessário reconhecer a subvenção no período no qual se torna recebível, com a divulgação adequada de forma a assegurar que os efeitos sejam claramente compreendidos.

Ainda sobre as subvenções governamentais, como se tratam de subsídios concedidos pelo Governo, através de dinheiro público destinado as entidades privadas, com a finalidade de retornar para a sociedade em forma de desenvolvimento de regiões e fomento do mercado, por

R. Eletr. do Alto Vale do Itajaí - REAVI, v. 7, n. 11, p. 01-09, dez., 2018 ISSN: 2316-4190, DOI: $10.5965 / 2316419007112018131$ 
exemplo, é de suma importância que as informações pertinentes às subvenções recebidas pelas entidades estejam de acordo com o CPC 07 (R1, 2010) no que se refere a sua divulgação, tanto para os usuários internos, quanto externos (RIOS; MARION, 2017).

Com base no exposto, é possível aferir que o profissional contábil por meio dos seus instrumentos de trabalho como a correta evidenciação dos fatos ocorridos na entidade, assim como, a divulgação das informações contábeis, tem um papel valoroso como emissor da informação contábil útil. Do mesmo modo, com a modernização dos processos das entidades proveniente do fácil acesso à informação, as entidades reconhecem a importância da oportuna evidenciação contábil e compreendem que evidenciar suas informações contábeis de acordo com os pronunciamentos e regulamentos dos órgãos responsáveis só beneficia a empresa com maior notabilidade por parte dos usuários externos.

\subsection{Estudos Anteriores}

Para a realização desta pesquisa foi realizada uma busca sobre os estudos anteriores pertinentes a temática de subvenções governamentais nas bases de dados da Scientific Periodicals Eletronic Library (SPELL) e Google Acadêmico.

As palavras-chave utilizadas na busca foram: subvenção governamental, subvenções governamentais, CPC 07, evidenciação contábil e disclosure. O Quadro 1 demonstra os estudos semelhantes identificados.

Quadro 1 - Pesquisas correlatas sobre subvenções governamentais

\begin{tabular}{|c|c|c|}
\hline Autores & Objetivo e período analisado & Resultados \\
\hline $\begin{array}{l}\text { Goulart } \\
(2010)\end{array}$ & $\begin{array}{l}\text { Objetivou analisar se as empresas de capital } \\
\text { aberto, listadas na BM\&FBovespa, realizaram a } \\
\text { evidenciação contábil das subvenções } \\
\text { governamentais de acordo com o CPC } 07 \text { nos } \\
\text { anos de } 2008 \text { e } 2009 \text {. }\end{array}$ & $\begin{array}{l}\text { O Autor concluiu que a maioria das empresas } \\
\text { pesquisadas não apresenta de forma } \\
\text { apropriada às informações referentes às } \\
\text { subvenções governamentais conforme é } \\
\text { divulgado no CPC } 07 .\end{array}$ \\
\hline $\begin{array}{l}\text { Loureiro, } \\
\text { Gallon, Luca } \\
(2011)\end{array}$ & 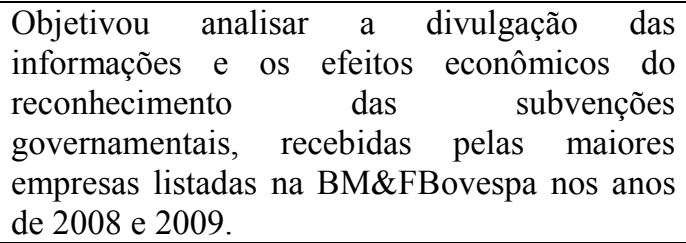 & $\begin{array}{l}\text { Os autores constataram que as empresas } \\
\text { apresentam um nível de evidenciação } \\
\text { considerado baixo, em média a } 30,4 \% \text { em } \\
2008 \text { e a } 33,3 \% \text { em } 2009 \text {, dos requisitos de } \\
\text { divulgação do CPC } 07 .\end{array}$ \\
\hline $\begin{array}{l}\text { Benetti et al. } \\
(2014)\end{array}$ & $\begin{array}{l}\text { O objetivo do trabalho foi verificar o nível de } \\
\text { evidenciação das Subvenções e Assistências } \\
\text { Governamentais (SAG's), com a publicação do } \\
\text { CPC } 07 \text {, referentes ao ano de } 2010 \text {. }\end{array}$ & $\begin{array}{l}\text { Concluiu-se que a maior apresentação de } \\
\text { evidenciação se refere à evidenciação da } \\
\text { política contábil adotada pela empresa quanto } \\
\text { as SAG's, incluindo os métodos de } \\
\text { apresentação nas demonstrações contábeis das } \\
\text { entidades. }\end{array}$ \\
\hline Silva (2015) & $\begin{array}{l}\text { O propósito do trabalho foi de verificar o nível } \\
\text { de evidenciação das subvenções } \\
\text { governamentais das companhias brasileiras } \\
\text { listadas na BM\&FBovespa em relação ao } \\
\text { Pronunciamento do CPC } 07 \text { em } 2013 \text {. }\end{array}$ & $\begin{array}{l}\text { Foi concluído que as empresas obtiveram } \\
\text { maior nível de evidenciação das subvenções } \\
\text { governamentais no que se refere às } \\
\text { discriminações das características de } \\
\text { subvenções. }\end{array}$ \\
\hline Saac (2016) & $\begin{array}{l}\text { O trabalhou objetivou-se em descrever as } \\
\text { características que classificam as empresas que } \\
\text { se beneficiam por subvenções e assistências } \\
\text { governamentais, listadas pelo índice IBRX-100 } \\
\text { da BM\&Fbovespa, entre os anos de } 2008 \text { e } \\
2014 \text {. }\end{array}$ & $\begin{array}{l}\text { Concluiu-se que as características } \\
\text { apresentadas nas empresas são significantes } \\
\text { para avaliar a probabilidade de determinada } \\
\text { empresa usufruir ou não de subvenções } \\
\text { governamentais e a adesão às normas } \\
\text { internacionais de contabilidade para aumento } \\
\text { na evidenciação do recebimento das mesmas. }\end{array}$ \\
\hline
\end{tabular}

R. Eletr. do Alto Vale do Itajaí - REAVI, v. 7, n. 11, p. 01-09, dez., 2018 ISSN: 2316-4190, DOI: 
Fonte: Elaborada pelos autores.

Nos estudos anteriores é possível verificar que as conclusões obtidas demonstraram que as entidades, de modo geral, não estão evidenciando de maneira correta e/ou completa às informações referente às subvenções governamentais recebidas, mesmo a partir da vigência do CPC 07 e sua posterior revisão CPC 07 (R1).

Benetti et al. (2014) levantaram em seus estudos que apesar de encontrarem alusões às subvenções governamentais nos demonstrativos contábeis e notas explicativas, as companhias efetuaram de forma parcial as evidenciações das demonstrações contábeis, não atendendo plenamente o Pronunciamento vigente.

Dessa forma, os estudos semelhantes demonstram que não houve melhora no que tange a evidenciação das subvenções governamentais, como é o exemplo dos trabalhos de Loreiro, Gallon e Luca (2011) e Silva (2015). Resultados estes que sugere à necessidade da confecção de maiores pesquisas no tocante a evidenciação das subvenções governamentais recebidas pelas entidades beneficiadas.

\section{Metodologia da pesquisa}

\subsection{Delineamento da Pesquisa}

No que tange ao objetivo geral do trabalho é possível identificar que a pesquisa se caracteriza como descritiva, pois para atingir o objetivo de identificar as características relacionadas ao nível de evidenciação das subvenções governamentais nas companhias brasileiras de capital aberto, é necessário relatar a situação identificada nas companhias verificadas, em relação ao nível de evidenciação das subvenções governamentais. Acevedo (2013) acrescenta que os conhecimentos produzidos pela pesquisa descritiva são essências para fomentar outras pesquisas que visem explicar o fenômeno abordado por ela.

Quanto à abordagem do problema, esta pesquisa caracteriza-se como qualitativa. De acordo com Marion et al. (2010), a pesquisa qualitativa é aquela que tem por objetivo conhecer e realizar a interpretação dos fenômenos sociais através dos significados que estes têm para as pessoas. No estudo qualitativo as respostas não são objetivas e o propósito é compreender o comportamento do determinado objeto de estudo, nesta abordagem não é utilizado um ferramental estatístico na análise dos dados.

No que diz respeito à obtenção dos dados a pesquisa é considerada documental, visto que os mesmos foram obtidos nas notas explicativas, DRE e BP das companhias da amostra. Segundo Beuren (2006), a pesquisa documental baseia-se em materiais que ainda não receberam um tratamento analítico ou que podem ser reelaborados de acordo com os objetivos da pesquisa. Os documentos analisados nesta pesquisa referem-se ao ano de 2016.

\subsection{Instrumento da Pesquisa}

Com a finalidade de mensurar o nível de evidenciação das subvenções governamentais por parte das companhias de capital aberto brasileiras, listadas na B3, foi elaborada uma lista de verificação com os itens considerados relevantes que devem constar nas informações

R. Eletr. do Alto Vale do Itajaí - REAVI, v. 7, n. 11, p. 01-09, dez., 2018 ISSN: 2316-4190, DOI: $10.5965 / 2316419007112018131$ 
divulgadas pelas companhias, de acordo com o CPC 07 (R1, 2010). No Quadro 2 estão expostas as determinações de divulgação das subvenções governamentais.

Quadro 2 - Lista de verificação para subvenções governamentais.

\begin{tabular}{|c|l|}
\hline Itens & \multicolumn{1}{c|}{ Itens da lista de verificação } \\
\hline I & Divulgação do tipo de subvenção recebida. \\
\hline II & Divulgação do nome do programa que fornece a subvenção. \\
\hline III & Divulgação do valor da subvenção. \\
\hline IV & Exposição da fonte da subvenção: municipal, estadual ou federal. \\
\hline V & Divulgação do prazo de contemplação da subvenção na empresa. \\
\hline VI & Para subvenção tributária, divulgação do tributo beneficiado. \\
\hline VII & Para subvenção de imobilizado, divulgação do valor da depreciação. \\
\hline VIII & Existência de informação se a subvenção é condicional. \\
\hline IX & $\begin{array}{l}\text { Divulgação na Demonstração do Resultado do Exercício (DRE) de qual item esta alocada a } \\
\text { receita proveniente da subvenção governamental. }\end{array}$ \\
\hline X & Exposição no passivo de qual a conta foi alocada a subvenção governamental. \\
\hline XI & Na ocorrência de perda da subvenção governamental, foi informado o motivo. \\
\hline
\end{tabular}

Fonte: Adaptado do CPC 07 (R1, 2010).

A lista de verificação está divida em 11 itens que exprimem os quesitos estabelecidos pelo CPC 07 (R1, 2010) necessários na divulgação das informações de subvenções governamentais das companhias brasileiras de capital aberto, listadas na B3. Através da pesquisa dos itens da lista de verificação nas notas explicativas das companhias, foi possível ter uma percepção do que está sendo divulgado pelas companhias, bem como medir o nível de evidenciação das mesmas.

\subsection{Procedimento de Pesquisa}

Pesquisar cientificamente é a busca de conhecimentos por meio de procedimentos capazes de dar confiabilidade aos resultados (PRODANOV; FREITAS, 2013). Considerando isso, para a realização desta pesquisa, o nível de evidenciação foi medido por meio de um índice de evidenciação calculado a partir da lista de verificação confeccionada baseada no CPC 07 (R1, 2010).

A partir da lista de verificação, como metodologia de cálculo do índice de evidenciação foi atribuído 1 (um ponto) nos casos em que verificou-se a evidenciação total do item, 0,50 (meio ponto) nos casos em que o item foi divulgado de maneira parcial, 0 (zero) para os casos em que não houve a evidenciação do item e NA (Não se Aplica) para os casos em que determinado item da lista não se aplicou para a divulgação da informação da companhia, estes parâmetros foram baseados no estudo de Souza (2015).

Deste modo, para efetuar o cálculo do índice de evidenciação, foi realizada a soma total dos itens divulgados pela companhia, dividido pelo número total de itens da lista de verificação, subtraído dos itens que receberam NA, conforme demonstrado na fórmula a seguir:

$$
\text { Índice de Evidenciação }=\frac{\text { Soma total dos itens divulgados }}{- \text { Total de itens da lista - NA }}
$$

O cálculo do índice de evidenciação foi aplicado individualmente por companhia para posterior análise e comparação dos resultados obtidos, permitindo também conhecer aquelas que obtiveram os maiores e menores índices da amostra.

Com o intuito de atingir o objetivo desta pesquisa, além de verificar o nível de evidenciação das companhias da amostra, averiguaram-se, também, as características das R. Eletr. do Alto Vale do Itajaí - REAVI, v. 7, n. 11, p. 01-09, dez., 2018 ISSN: 2316-4190, DOI: 
mesmas, visando identificar sinais de uma possível relação, estas que foram: setor de atuação, empresa que realiza a auditoria e o resultado líquido do exercício. A seguir estão apresentadas as justificativas para escolha das referidas características analisadas no presente trabalho.

\subsubsection{Ramo de Atuação}

Foi realizada uma análise por subsetor das companhias da amostra listadas na B3, com o intuito de identificar se existe alguma relação entre a classificação setorial das empresas com seu nível de evidenciação das subvenções governamentais. As informações relativas ao subsetor das companhias foram coletadas através do site da B3.

\subsubsection{Empresa de Auditoria}

A auditoria das demonstrações contábeis concebe o conjunto de procedimentos técnicos que tem por objetivo a emissão de parecer sobre sua adequação, conforme as normas de Contabilidade e legislações específicas (CREPALDI, 2016). Visto isso, espera-se que as companhias que receberam parecer sem ressalva, estejam seguindo com a evidenciação e divulgação de suas informações conforme as normas de contabilidade, como é o caso do pronunciamento contábil CPC 07 (R1).

Para a presente pesquisa, analisou-se a relação entre a empresa de auditoria da companhia com o nível de evidenciação que a mesma obteve, para a averiguação se existe tendência de relação entre maiores ou menores índices de evidenciação com o fato de ser auditada por big four ou outras empresas de auditora.

\subsubsection{Resultado Líquido do Exercício}

De acordo com Araújo (2008), o resultado líquido do exercício é obtido através da apuração das receitas e despesas do período, em complemento, Rios e Marion (2017), evidenciam que o resultado líquido do exercício é aquela parcela do resultado que efetivamente ficou à disposição dos sócios para ser retirada ou reinvestida. Dessa forma, o resultado do exercício é uma medida de desempenho das companhias.

Para a presente pesquisa, foi analisada a relação entre o resultado líquido do exercício de 2016 que as companhias obtiveram, adquirido através da demonstração do resultado do exercício publicado pela companhia, com seu respectivo o nível de evidenciação das subvenções governamentais.

\subsection{Amostra da Pesquisa}

Para obtenção da amostra de pesquisa foi necessário, primeiramente, realizar um levantamento de todas as companhias de capital aberto brasileiras listadas na B3, sendo estas um total de 451 companhias na data de 15/08/2017. Deste preliminar levantamento foram desconsideradas as instituições financeiras que equivalem a 37 companhias, pelo fato de seu órgão regulador, o BACEN, não aderir ao pronunciamento CPC 07 (R1, 2010). Desta forma, restaram 414 companhias para análise.

Foram analisadas as notas explicativas de 414 companhias referentes ao exercício social de 2016, para averiguação de quais possuíam qualquer tipo de subvenção governamental, dessas companhias analisadas, 154 não possuíam nenhum registro de recebimento de subvenção governamental no ano de 2016 ou anos anteriores em que ainda houvesse impacto nos lançamentos por apropriação da receita pela companhia. Por conseguinte, a amostra final

R. Eletr. do Alto Vale do Itajaí - REAVI, v. 7, n. 11, p. 01-09, dez., 2018 ISSN: 2316-4190, DOI: $10.5965 / 2316419007112018131$ 
totalizou 260 empresas nas quais foram identificadas, no mínimo, algum tipo de subvenção governamental recebida, conforme evidencia o Quadro 3.

Quadro 3 - Pesquisa de companhias para a composição da amostra.

\begin{tabular}{|l|c|}
\hline \multicolumn{1}{|c|}{ Apuração da amostra da pesquisa } & Número de companhias \\
\hline Total de companhias listas na B3 para verificação em 15/08/2017 & 451 \\
\hline (-) Instituições financeiras & -37 \\
\hline (-) Companhias que não possuíam nenhuma subvenção governamental & -154 \\
\hline (=) Total da amostra final para realização da pesquisa & 260 \\
\hline
\end{tabular}

Fonte: Elaborada pelos autores.

O Quadro 3 evidencia de maneira mais compreensível visualmente, os parâmetros para a apuração da amostra da pesquisa, no qual é possível aferir que a amostra deste trabalho se constituiu de 260 companhias de capital aberto listadas na B3, as informações analisadas foram referentes ao exercício social de 2016.

\section{Resultados da pesquisa}

\subsection{Análise do Nível de Evidenciação das Companhias Auditadas por Big Four e Outras Empresas de Auditoria}

Após a coleta de dados foram analisados os seguintes tópicos: Análise do nível de evidenciação das companhias auditadas por big four e outras empresas de auditoria; Análise do nível de evidenciação com a relação do resultado do exercício no ano de 2016; Análise do nível de evidenciação em relação aos subsetores da B3; Análise do nível de evidenciação das empresas que obtiveram as maiores classificações do índice de evidenciação; e Análise do nível de evidenciação das empresas que obtiveram as menores classificações do índice de evidenciação. A Tabela 1 demonstra a média do nível de evidenciação das companhias auditadas no exercício social de 2016 por big four e outras auditorias.

Tabela 1 - Classificação das companhias pela empresa de auditoria.

\begin{tabular}{lc}
\hline Empresa de Auditoria & $\begin{array}{c}\text { Média do Nível } \\
\text { de Evidenciação }\end{array}$ \\
\hline Ernst \& Youg - big four & $25 \%$ \\
\hline Pricewaterhousecoopers - big four & $25 \%$ \\
\hline Deloitte Touche Tohmatsu - big four & $24 \%$ \\
\hline KPMG - big four & $17 \%$ \\
\hline Outras empresas de auditoria & $17 \%$ \\
\hline Fonte: Dados da pesquisa.
\end{tabular}

As maiores médias de evidenciação das subvenções governamentais identificadas foram de três das quatro empresas de auditoria classificadas como big four, que são: Ernst \& Youg, Pricewaterhousecoopers e Deloitte Touch Tohmatsu. Já as companhias auditadas pela big four KPMG apresentaram a mesma média do nível de evidenciação que aquelas auditadas pelas outras empresas de auditorias. $\mathrm{O}$ que não sugere uma tendência de companhias auditadas por big four possuírem maiores níveis de evidenciação.

Estes resultados corroboram com os estudos de Loureiro, Gallon e Luca (2011), em que não foi possível confirmar qualquer relação entre os níveis de evidenciação das subvenções governamentais com o fato de ser auditada por big four.

Os resultados obtidos pela análise do nível de evidenciação com a característica de empresas de auditoria evidenciam o quão baixo é a evidenciação das informações das subvenções governamentais recebidas pelas companhias, tanto das companhias auditadas por

R. Eletr. do Alto Vale do Itajaí - REAVI, v. 7, n. 11, p. 01-09, dez., 2018 ISSN: 2316-4190, DOI: 10.5965/2316419007112018131 
big four, quanto das demais empresas auditadas por outras empresas de auditoria, visto que as maiores médias não alcançam nem 50\% de evidenciação das informações, fato que indica uma deficiência por parte das companhias.

\subsection{Análise do Nível de Evidenciação com a relação do Resultado do Exercício no ano de 2016}

A Tabela 2 demonstra a relação entre a média do nível de evidenciação das companhias que tiveram lucro e prejuízo no exercício social de 2016.

\begin{tabular}{clc}
\multicolumn{3}{l}{ Tabela 2 - Nível de evidenciação X resultado do exercício da companhia em 2016 } \\
$\begin{array}{clc}\text { Quantidade de } \\
\text { Empresas }\end{array}$ & $\begin{array}{c}\text { Resultado do Exercício de } \\
\mathbf{2 0 1 6}\end{array}$ & $\begin{array}{c}\text { Média do Nível de } \\
\text { Evidenciação }\end{array}$ \\
\hline 95 & Prejuízo & $21 \%$ \\
\hline 165 & Lucro Líquido & $21 \%$ \\
\hline Fonte: Dados da pesquisa.
\end{tabular}

Através dos dados analisados, não é possível afirmar que há relação entre o resultado do exercício ser positivo ou negativo com a evidenciação das subvenções governamentais, visto que a média de evidenciação de ambos os casos foi idêntica.

Além disso, também, não se pode afirmar que o recebimento dos auxílios governamentais para subsidiar as atividades fins das empresas intervenha beneficamente para obtenção de um resultado positivo no exercício social da mesma, considerando que os dados coletados demonstram que 36,54\% (95) das companhias tiveram prejuízo no exercício social de 2016, enquanto 63,46\% (165) das companhias da amostra apuraram lucro no referido exercício.

\subsection{Análise do nível de evidenciação e a relação dos subsetores da $B 3$}

A Tabela 3 apresenta os 45 subsetores de companhias da B3, classificados pela quantidade de companhias que os contemplam e relacionados às suas respectivas médias do nível de evidenciação das subvenções governamentais.

Tabela 3 - Análise da média do nível de evidenciação em relação aos subsetores das companhias

\begin{tabular}{clc}
\hline Quantidade de Empresas & \multicolumn{1}{c}{ Subsetor } & Média do Nível de Evidenciação \\
\hline 52 & Energia elétrica & $24 \%$ \\
\hline 30 & Transporte & $9 \%$ \\
\hline 18 & Tecidos, vestuário e calçados & $41 \%$ \\
\hline 17 & Outros & $20 \%$ \\
\hline 14 & Alimentos processados & $22 \%$ \\
\hline 10 & Comércio & $21 \%$ \\
\hline 10 & Máquinas e equipamentos & $18 \%$ \\
\hline 7 & Petróleo, Gás e Combustível & $29 \%$ \\
\hline 7 & Material de Transporte & $18 \%$ \\
\hline 6 & Madeira e Papel & $29 \%$ \\
\hline 6 & Construção Civil & $15 \%$ \\
\hline 6 & Programas e Serviços & $14 \%$ \\
\hline 6 & Agropecuária & $14 \%$ \\
\hline 6 & Telecomunicações & $10 \%$ \\
\hline 5 & Viagens e Lazer & $36 \%$ \\
\hline 5 & Comércio e Distribuição & $28 \%$ \\
\hline 5 & Siderúrgica e Metalúrgica & $23 \%$ \\
\hline 5 & Água e Saneamento & $16 \%$ \\
\hline
\end{tabular}

R. Eletr. do Alto Vale do Itajaí - REAVI, v. 7, n. 11, p. 01-09, dez., 2018 ISSN: 2316-4190, DOI: $10.5965 / 2316419007112018131$ 


\begin{tabular}{llc}
\hline 5 & Exploração de Imóveis & $0 \%$ \\
\hline 4 & Químicos & $36 \%$ \\
\hline 4 & Serviços Méd. Hosp. Análise Diag. & $22 \%$ \\
\hline 4 & Construção e Engenharia & $20 \%$ \\
\hline 4 & Medicamentos e Outros Produtos & $0 \%$ \\
\hline 3 & Automóveis e Motocicletas & $10 \%$ \\
\hline 2 & Produtos Uso Pessoal e Limpeza & $36 \%$ \\
\hline 2 & Securitizadoras e Resseguros & $25 \%$ \\
\hline 2 & Previdência e Seguros & $24 \%$ \\
\hline 2 & Utilidades Domésticas & $22 \%$ \\
\hline 2 & Computadores e Equipamentos & $17 \%$ \\
\hline 2 & Gás & $3 \%$ \\
\hline 2 & Serviços Financeiros Diversos & $0 \%$ \\
\hline 1 & Embalagens & $67 \%$ \\
\hline 1 & Bebidas & $44 \%$ \\
\hline 1 & Equipamentos & $37,50 \%$ \\
\hline 1 & Mineração & $33 \%$ \\
\hline 1 & Intermediários e Financeiro & $22 \%$ \\
\hline 1 & Hotéis e Restaurantes & $0 \%$ \\
\hline 1 & Mídia & $0 \%$ \\
\hline
\end{tabular}

Fonte: Dados da pesquisa.

Conforme evidenciado na Tabela 3, é possível notar que os subsetores de Energia elétrica e Transportes, contemplam o maior número de companhias da amostra, com respectivamente, $20 \%$ (52) e 11,54\% (30) do total de companhias analisadas. Mesmo com o volumoso número de companhias que atuam no mesmo subsetor, recebendo possivelmente subvenções governamentais de caráter semelhante, o que poderia sugerir maior destreza na evidenciação devido aos vários exemplos existentes e conhecimento iterado dos profissionais, a média do nível de evidenciação é muito baixa, sendo $24 \%$ para o subsetor de Energia elétrica e 9\% para Transportes.

Os demais subsetores da amostra, também evidenciaram médias muito baixas, salvo os subsetores de Embalagens e Bebidas, que se destacaram com a maior média de evidenciação das subvenções governamentais, sendo 67\% para o subsetor de Embalagens, composto pela companhia Metalgráfica Iguaçu S.A. e, com 44\% o subsetor de bebidas composto pela companhia Ambev S.A.

O subsetor "Outros" exposto na Tabela 3 representa, na verdade, mais três subsetores além de Outros, que são: Serviços, Não Classificados e Diversos. Por se tratarem de denominações genéricas, que não conseguem exprimir o conceito das atividades dos subsetores, foram atribuídos sob a classificação de Outros, contemplando 17 companhias no total, com uma média do nível de evidenciação de $20 \%$.

Em Suma, conforme é possível constar na Tabela 3, não foram verificadas altas médias de nível de evidenciação nos subsetores analisados, não gerando margens de tendências de que determinados subsetores da amostra pendam evidenciar mais ou menos que outros subsetores, nem mesmo os subsetores com maiores quantidades de companhias classificadas, a exemplos: energia elétrica e transportes.

\subsection{Análise do Nível de Evidenciação das Empresas que Obtiveram as Maiores Classificações do índice de Evidenciação}

Conforme foi proposto no objetivo específico três, de elaborar um ranking com os maiores e menores índices de evidenciação das subvenções governamentais das companhias, a Tabela 4 demonstra o ranking de classificação das companhias que obtiveram os dez maiores índices de evidenciação das subvenções governamentais.

R. Eletr. do Alto Vale do Itajaí - REAVI, v. 7, n. 11, p. 01-09, dez., 2018 ISSN: 2316-4190, DOI: $10.5965 / 2316419007112018131$ 
Tabela 4: Ranking de classificação das companhias que obtiveram os maiores níveis de evidenciação das subvenções governamentais

\begin{tabular}{c|c|c}
\hline Posição & Quantidade de Companhias & Nível de Evidenciação \\
\hline $1^{\circ}$ & 4 & $78 \%$ \\
\hline $2^{\circ}$ & 9 & $67 \%$ \\
\hline $3^{\circ}$ & 2 & $62 \%$ \\
\hline $4^{\circ}$ & 2 & $61 \%$ \\
\hline $5^{\circ}$ & 7 & $55 \%$ \\
\hline $6^{\circ}$ & 2 & $50 \%$ \\
\hline $7^{\circ}$ & 17 & $44 \%$ \\
\hline $8^{\circ}$ & 10 & $39^{\circ}$ \\
\hline $9^{\circ}$ & 1 & $37,50 \%$ \\
\hline $1^{\circ}$ & 4 & $37 \%$ \\
\hline
\end{tabular}

Fonte: Dados da pesquisa.

Através da Tabela 4 pode-se verificar que o maior índice atingiu 78\% de nível de evidenciação das subvenções governamentais, que corresponde a apenas $1,54 \%$ das companhias da amostra. Em sequência, as posições de segundo, terceiro, quarto, quinto e sexto lugar, representando $8,46 \%$ do total da amostra, também conseguiram obter um índice igual ou superior a 50\% do nível de evidenciação das informações de subvenções governamentais recebidas pelas companhias. Resultados estes que representam a pequena expressão do número de companhias que alcançaram níveis consideravelmente bons, no que se refere à evidenciação das subvenções governamentais.

Analisando a diferença de valores do nível de evidenciação do primeiro lugar na posição do ranking, com $78 \%$ para a segunda posição, $67 \%$ equivale a $14,10 \%$, uma diferença considerável, bem como, a comparação com a primeira e última posição da tabela, sendo a última posição formada pelo valor de $37 \%$ do nível de evidenciação, a essa diferença apurouse $40,99 \%$ de diferença no nível de evidenciação das empresas constantes na décima posição no ranking em relação às primeiras. Esses resultados vão ao encontro com as conclusões do estudo de Loureiro, Gallon e Luca (2011).

\subsection{Análise do Nível de Evidenciação das Empresas que Obtiveram as Menores classificações do Índice de Evidenciação}

A Tabela 5 demonstra o ranking de classificação das companhias que obtiveram os dez menores índices de evidenciação das subvenções governamentais.

Tabela 5. Ranking de classificação das companhias que obtiveram os menores níveis de evidenciação das subvenções governamentais

\begin{tabular}{c|c|c}
\hline Posição & $\begin{array}{c}\text { Quantidade de } \\
\text { Companhias }\end{array}$ & $\begin{array}{c}\text { Nível de } \\
\text { Evidenciação }\end{array}$ \\
\hline $1^{\mathrm{o}}$ & 89 & $0 \%$ \\
\hline $2^{\mathrm{o}}$ & 3 & $5 \%$ \\
\hline $3^{\mathrm{o}}$ & 1 & $6 \%$ \\
\hline $4^{\mathrm{o}}$ & 14 & $11 \%$ \\
\hline $5^{\mathrm{o}}$ & 5 & $12 \%$ \\
\hline $6^{\mathrm{o}}$ & 12 & $17 \%$ \\
\hline $7^{\mathrm{o}}$ & 7 & $19 \%$ \\
\hline $8^{\mathrm{o}}$ & 29 & $22 \%$ \\
\hline
\end{tabular}

R. Eletr. do Alto Vale do Itajaí - REAVI, v. 7, n. 11, p. 01-09, dez., 2018 ISSN: 2316-4190, DOI: 


\begin{tabular}{c|c|c}
$9^{\circ}$ & 14 & $25 \%$ \\
\hline $10^{\circ}$ & 8 & $28 \%$ \\
\hline
\end{tabular}

Fonte: Dados da pesquisa.

Verifica-se na Tabela 5 que é considerável o número de companhias que obtiveram o nível (índice) de evidenciação igual à zero na evidenciação das subvenções governamentais, um total de 34,23\% que equivale a 89 companhias da amostra, uma situação preocupante, considerando que estas companhias receberam recursos públicos.

Ressalta-se a respeito dessas companhias com nível de evidenciação igual a zero que, na maior parte dessas empresas as subvenções governamentais identificadas foram de financiamentos adquiridos pelo Banco Nacional do Desenvolvimento Econômico e Social (BNDES), mas que não foram evidenciados como subvenções governamentais, apesar de o CPC 07 (R1) identificar tais financiamentos como subsídios governamentais. Fato este que chama atenção, visto que são recursos públicos que deveriam estar sendo evidenciados de maneira adequada, conforme alude o CPC 07 (R1).

Em consonância com o estudo de Loureiro, Gallon e Luca (2011), realizado com a amostra das companhias nos exercícios sociais de 2008 e 2009, quando da vigência da primeira publicação do CPC 07, revogado em 2010, os resultados obtidos apontaram um baixo nível de evidenciação das subvenções governamentais por parte das companhias brasileiras. Através do presente estudo, foi encontrado o mesmo resultado, com amostra e exercício social analisado diferente, bem como, utilizados das especificações do pronunciamento vigente do CPC 07 (R1, 2010).

Em acordo o estudo de Silva (2015), também destaca o baixo nível de evidenciação das subvenções governamentais, acrescentando que as companhias não realizaram a evidenciação completa conforme informações determinadas pelo CPC 07 (R1, 2010).

\section{Conclusões da pesquisa}

Em relação ao objetivo geral desta pesquisa, foi possível verificar o nível de evidenciação das companhias analisadas em relação às informações divulgadas referentes às subvenções governamentais, bem como, relacionar e explanar com algumas características das companhias da amostra, sendo estas: empresa de auditoria, resultado do exercício e os subsetores da B3 em que essas companhias estão classificadas.

Quanto aos objetivos específicos abordados, de elaborar uma lista de verificação com o intuito de medir o nível de evidenciação das subvenções governamentais das companhias, foi atingido. Para cumprir esse objetivo foi elaborado um checklist com 11 itens para averiguar e medir às informações divulgadas pelas companhias, esses itens foram baseados nos critérios do CPC 07 (R1) que objetiva prescrever o registro contábil e a divulgação das subvenções governamentais pelas companhias beneficiadas. No que se refere a mensurar o nível de evidenciação das subvenções governamentais nas companhias analisadas, foi atingido. Para esse feito foram analisadas as notas explicativas, a demonstração do resultado do exercício e o balanço patrimonial de todas as companhias da amostra e, posteriormente, atribuído uma pontuação para as questões respondidas do checklist, em relação à quantidade das informações que as companhias divulgaram sobre as subvenções governamentais e, seguidamente, $o$ resultado obtido foi apresentado através de um percentual.

Foi elaborado, também, um ranking das companhias com maiores e menores níveis de evidenciação das subvenções governamentais e a comparação do nível de evidenciação das companhias analisadas com as características delimitadas pela pesquisa.

Através das análises efetuadas, pode-se verificar como resultados da pesquisa que a maioria das companhias analisadas apresentou um baixo nível de evidenciação das subvenções

R. Eletr. do Alto Vale do Itajaí - REAVI, v. 7, n. 11, p. 01-09, dez., 2018 ISSN: 2316-4190, DOI: $10.5965 / 2316419007112018131$ 
governamentais, sendo que destas apenas $10 \%$ da amostra atingiram uma média maior ou igual a $50 \%$ do nível de evidenciação. Esse resultado chama a atenção, visto que se trata de recursos provenientes de dinheiro público destinado a companhias, para a finalidade de fomentar as atividades fins das mesmas e, consequentemente, prover mais oportunidades e recursos para a população.

As conclusões desta pesquisa corroboram com os estudos de Silva (2015), que concluiu que as companhias analisadas apresentaram um baixo nível de evidenciação, pois não realizaram a divulgação completa dos itens conforme instrui o CPC 07 (R1), como também, o estudo de Goulart (2010) que observou que a maiorias das empresas de sua amostra não apresentaram informações completas referentes às subvenções governamentais recebidas. Além do intento principal das subvenções governamentais, outro ponto importante abordado neste trabalho, foi que as companhias que receberam ou já contavam com haveres procedentes de subvenções governamentais no exercício social de 2016, contam com as instruções normativas do CPC 07 (R1), no que tange a adequada evidenciação deste tipo de captação. Isto é, possuem a elucidação de como deveriam conduzir em seus demonstrativos contábeis e notas explicativas as subvenções governamentais recebidas.

Através das análises das características das companhias analisadas não foi possível identificar qualquer tendência de relação entre a empresa de auditoria, subsetor e o resultado do exercício no período apurado com o nível de evidenciação das companhias, sugerindo que o baixo nível de evidenciação das companhias não possa ser apontado a apenas um fator específico. Estes resultados reforçam os estudos de Loureiro, Gallon e Luca (2011), que não conseguiram averiguar a relação entre o nível de evidenciação das subvenções governamentais em relação aos setores das companhias, exceto para o setor têxtil.

Concluiu-se que a maior parte das companhias brasileiras listadas na B3, beneficiadas por subvenções governamentais no exercício social de 2016 não realizaram a apropriada divulgação das subvenções governamentais recebidas, isto é, não cumpriram integralmente com o Pronunciamento Técnico do CPC 07 (R1).

Com base no trabalho realizado, foi possível verificar, no que tange ao tratamento das companhias brasileiras às subvenções governamentais, que ainda há muito a ser explorado sobre o tema. Visto que é um assunto ainda pouco explorado academicamente e pouco retratado pelas empresas que se beneficiam.

Embora se tenha obtido, de modo geral, um conhecimento sobre a realidade dos tratamentos dados as subvenções governamentais pelas companhias, é necessária a realização de mais estudos que contemplem este tema. Sendo assim, como proposta para pesquisas futuras seria interessante a realização de uma análise utilizando um ferramental estatístico visando identificar alguma relação de causa e efeito entre o nível de evidenciação e as características da companhia.

\section{Referências}

ACEVEDO, Claudia Rosa; NOHARA, Jouliana Jordan. Como fazer monografias: TCC, Disertações e Teses. 4. ed. São Paulo: Editora Atlas S.A., 2013.

B3 S.A. - BRASIL, BOLSA, BALCÃO. Introdução sobre os segmentos de listagem. Disponível em: <http://www.bmfbovespa.com.br/pt_br/listagem/acoes/segmentos-delistagem/sobre-segmentos-de-listagem/>. Acesso em: 11 abr. 2018.

BENETTI, Kelen; BENETTI, Karen; BRAUN, Marli; ORO, Ieda Margarete; UTZIG, Mara Jaqueline Santore. Evidenciação de subvenção e assistência governamentais das empresas 
BM\&FBOVESPA. Revista Evidenciação Contábil \& Finanças, João Pessoa, 2014, v. 2, n. 1, p. 75-90, jan./abr., 2014.

BEUREN, Ilse Maria. Trajetória da construção de um trabalho monográfico em contabilidade. In: BEUREN, Ilse Maria (Org.). Como Elaborar Trabalhos Monográficos em Contabilidade: Teoria e Prática. 3. ed. São Paulo: Atlas S.A., 2006.

CPC - COMITÊ DE PRONUNCIAMENTO CONTÁBEIS. Estrutura Conceitual para Elaboração e Divulgação de Relatório Contábil-Financeiro - CPC 00 (R1). Aprovado na Deliberação CVM n ${ }^{\circ}$ 675, (2011, 02 de dezembro), que revoga o CPC 00 Aprovado pela Deliberação CVM $\mathrm{n}^{\circ}$ 539, (2008, 01 de novembro). 2011. Disponível em: $<$ http://www.cpc.org.br/CPC/Documentos-

Emitidos/Pronunciamentos/Pronunciamento?Id=80>. Acesso em: 10 de nov. 2017.

CPC 07 (R1): Subvenções e Assistências Governamentais. Aprovado na Deliberação $\overline{\mathrm{CVM} \mathrm{n}}^{\circ}$ 646, (2010, 02 de dezembro), que revoga o CPC 07 Aprovado pela Deliberação CVM $\mathrm{N}^{\mathrm{o}} 555$, (2008, 12 de novembro). 2010. Disponível em: $<$ http://static.cpc.mediagroup.com.br/Documentos/167_CPC_07_R1_rev\%2003.pdf> Acesso em: 15 de out. 2017.

CREPALDI, Guilherme Simões; CREPALDI, Silvio Aparecido. Auditoria Contábil: teoria e prática. 10. ed. São Paulo: Atlas, 2016.

FERNANDES, Luciane Alves, SANTOS, José Luiz dos, SCHMIDT, Paulo. Fundamentos de Contabilidade Internacional. v. 12. São Paulo: Atlas, 2006.

GOULART, Thiago Gonçalves. A divulgação das informações sobre a subvenção econômica pelas companhias abertas: uma análise das demonstrações financeiras padronizadas (DFPs) dos anos de 2008 e 2009. 2010. $74 \mathrm{f}$. Trabalho de Conclusão de Curso (Monografia) - Curso de Ciências Contábeis, Universidade Federal de Santa Catarina, Florianópolis, 2010.

IUDÍCIBUS, Sérgio de. Teoria da Contabilidade. 11. ed. São Paulo: Atlas, 2015.

LOUREIRO, Débora Queiroz; GALLON, Alessandra Vasconcelos; LUCA, Márcia Martins Mendes de. Subvenções e Assistências Governamentais (SAGs): Evidenciação e rentabilidade das maiores empresas brasileiras. Revista de Contabilidade e Organizações, São Paulo, 2011, v. 5, n. ${ }^{\circ} 13$, p. 34-54, 2011.

MARION, José Carlos; MARION, Márcia Maria Costa; TRALDI, Maria Cristina; DIAS, Reinaldo. Monografia Para os Cursos de Administração, Contabilidade e Economia. 2. ed. São Paulo: Editora Atlas S.A., 2010.

MULLER, Aderbal Nicolas, SCHERER, Luciano Márcio. Contabilidade Avançada e Internacional. 2. ed. São Paulo: Saraiva, 2011.

NIYAMA, Jorge Katsumi, SILVA, César Augusto Tibúrcio. Teoria da Contabilidade. 3. ed. São Paulo: Atlas, 2013. 
PRODANOV, Cleber Cristiano, FREITAS, Ernani Cesar de. Metodologia do Trabalho Científico: Métodos e Técnicas da Pesquisa e do Trabalho Acadêmico. 2. ed. Novo Hamburgo: Feevale, 2013.

REZENDE, Amaury José; DALMÁCIO, Flávia Zobóli. Avaliação do impacto dos incentivos fiscais sobre os retornos e as políticas de investimento e financiamentos das empresas. In: Congresso X Anpcont, 10., 2016, Ribeirão Preto. Anais eletrônicos... Disponível em: < http://congressos.anpcont.org.br/x/anais/files/2016-05/cue253.pdf $>$. Acesso em: 20 de nov. 2017.

RIOS, Ricardo Pereira, MARION, José Carlos. Contabilidade Avançada. São Paulo: Atlas, 2017.

SAAC, Diana Maria Preciado. Análise das características determinantes das empresas que usufruem de Subvenções e Assistências Governamentais. 2016. 78 f. Dissertação (mestrado em contabilidade) - Curso de Pós-Graduação em Controladoria e Contabilidade da Faculdade de Economia, Universidade de São Paulo, São Paulo, 2016.

SANTOS, José dos, SCHIMIDT, Paulo, MACHADO, Nilson Perinazzo. Fundamentos da Teoria da Contabilidade. v. 6. São Paulo: Atlas, 2005.

SILVA, Edson Cordeiro da. Governança Corporativa nas Empresas: guia prático de orientação para acionistas, investidores, conselheiros de administração e fiscal, auditores, executivos, gestores, analistas de mercado e pesquisadores. 4. ed. São Paulo: Atlas, 2016.

SILVA, Lisiane Gonçalves. Nível de evidenciação das subvenções governamentais nas companhias de capital aberto brasileiras no ano de 2013. 2015. $50 \mathrm{f}$. Trabalho de Conclusão de Curso (Monografia) - Curso de Ciências Contábeis, Universidade Federal de Santa Catarina, Florianópolis, 2015.

SOUZA, Nali de. Desenvolvimento regional. São Paulo. Atlas, 2009.

WEFFORT, Elionor Jreige. O Brasil e a harmonização contábil internacional: influências do sistema jurídico e educacional, da cultura e do mercado. São Paulo: Atlas, 2005. 